\title{
BMJ Open Patient preferences for nutritional supplementation to improve fracture healing: a discrete choice experiment
}

\author{
Elizabeth Nichols, ${ }^{1}$ Nathan N O'Hara, ${ }^{1}$ Yasmin Degani, ${ }^{1}$ Sheila A Sprague, ${ }^{2}$ \\ Jonathan D Adachi, ${ }^{3}$ Mohit Bhandari, ${ }^{2}$ Michael F Holick, ${ }^{4}$ Daniel W Connelly, ${ }^{1}$ \\ Gerard P Slobogean ${ }^{1}$
}

\begin{abstract}
To cite: Nichols E, O'Hara NN, Degani Y, et al. Patient preferences for nutritional supplementation to improve fracture healing: a discrete choice experiment. BMJ Open 2018;8:e019685. doi:10.1136/ bmjopen-2017-019685

- Prepublication history and additional material for this paper are available online. To view these files, please visit the journal online (http://dx.doi. org/10.1136/bmjopen-2017019685).
\end{abstract}

Received 18 September 2017 Revised 8 March 2018 Accepted 15 March 2018

Check for updates

${ }^{1}$ Department of Orthopaedics, University of Maryland School of Medicine, Baltimore, MD ${ }^{2}$ Department of Surgery, McMaster University, Hamilton, Ontario, Canada

${ }^{3}$ Department of Medicine, McMaster University, Hamilton, ON, Canada

${ }^{4}$ Department of Medicine

Endocrinology, Diabetes \&

Nutrition, Boston University,

Boston, Massachusetts, USA

Correspondence to

Nathan N O'Hara;

nohara@umoa.umm.edu

\section{ABSTRACT}

Objective Vitamin $D$ is often prescribed as an adjuvant therapy to aid fracture healing due to its biological role in bone health. However, the optimal frequency, dosage and duration of vitamin $\mathrm{D}$ supplementation for nonosteoporotic fracture healing has not been established. The objective of this study was to determine patient preferences for fracture healing relative to hypothetical vitamin D supplementation dosing options.

Design Discrete choice experiment.

Setting Level 1 trauma centre in Baltimore, Maryland, USA.

Participants 199 adult (18-60 years) patients with a fracture.

Primary outcome measures Parameter estimates of utility for fracture healing relative to dosing regimens were analysed using hierarchical Bayesian modelling.

Results A reduced risk of reoperation (34.3\%) and reduced healing time (24.4\%) were the attributes of greatest relative importance. The highest mean utility estimates were for a one-time supplementation dose ( $B=0.71,95 \% \mathrm{Cl} 0.41$ to 1.00 ) followed by a reduced risk of reoperation ( $B=0.41$ per absolute \% reduction, $95 \% \mathrm{Cl}$ 0.0 .36 to 0.46 ). Supplementation for 24 weeks in duration ( $B=-0.83,95 \% \mathrm{Cl}-1.00$ to -0.67 ) and a daily supplement ( $B=-0.29,95 \% \mathrm{Cl}-0.47$ to -0.11 ) had the lowest mean utilities. The 'no supplement' option had a large negative value suggesting supplementation was generally desirable in this sample population. Among other possible clinical scenarios, patients expected a $2 \%$ reduction in the absolute risk of reoperation or a 3.1-week reduction in healing time from the baseline to accept a treatment regimen requiring two separate doses of supplementation, two blood tests and a cost of $\$ 20$ within 3 months of injury. Conclusions Patients with orthopaedic trauma demonstrated strong willingness to take a vitamin D supplement that would decrease risk of reoperation and reduce healing time. Furthermore, these findings specify the required decrease in reoperation risk and reduction in healing time patients would expect to adhere to possible vitamin $\mathrm{D}$ dosing regimens.

\section{INTRODUCTION}

There has been a recent trend in the orthopaedic community to prescribe vitamin $\mathrm{D}$ as an adjuvant therapy to aid fracture healing
Strengths and limitations of this study

- The study quantifies the preferences of patients with orthopaedic trauma for plausible supplementation dosing regimens in contrast to the possible clinical benefits gained with supplementation.

- Risk-benefit trade-off estimates for common vitamin $D$ dosing regimens are provided.

- Given the directionality, magnitude, and consistency of the responses, high-face validity is assumed.

- The study analyses stated preferences of the respondents to hypothetical scenarios. Actual responses may differ.

due to its biological role in bone health and the observed prevalence of low-serum vitamin D levels among adult patients who had sustained a fracture. Recent studies have shown serum levels of vitamin D were found to be reduced during the curative period of a fracture, suggesting vitamin $D$ is used in the formation and mineralisation of the callus. ${ }^{1}$ These observations in the literature suggest vitamin D supplementation could play a role in improving fracture healing in healthy adults without a history of osteoporosis or metabolic bone diseases. Despite these associations between vitamin $\mathrm{D}$ levels and bone health, current literature is inconclusive on the most effective treatment strategy for prescribing vitamin $\mathrm{D}$ to patients with a fracture. Therefore, there is a need to determine the optimal frequency, dosage and duration of vitamin D supplementation for patients with a fracture.

From a demographic perspective, adult patients with a fracture are part of a larger trauma population that is associated with poor dietary health, low patient self-efficacy and a high likelihood of poor medication adherence. $^{2}$ To combat these factors, this study seeks to involve patients in the clinical decision-making process through the use of 
a discrete choice experiment (DCE) to understand what aspects of treatment are important to patients. DCEs are often used to elicit treatment preferences, particularly when several different treatment options are available. The success of these techniques have been demonstrated in other fracture populations, including comparing patient important attributes of osteoporosis treatments. ${ }^{3}$ Implementing guidelines that consider patient preferences may increase patient satisfaction with and improve adherence to clinical treatments. ${ }^{4}$ The purpose of this study was to determine patient preferences for vitamin D supplementation that may reduce healing times and the risk of complications, quantify risk-benefit trade-offs of possible regimens and costs, and determine the preference heterogeneity among respondents. We hypothesise that a reduction in the frequency and duration of supplementation will be preferred by patients with orthopaedic trauma. This study only assessed patient preferences and did not evaluate whether the preferred supplementation regimens are effective in reducing healing time or the risk of reoperation.

\section{METHODS \\ DCE}

We prospectively administered a DCE to patients with orthopaedic trauma at a level 1 trauma centre. DCEs are widely used in healthcare to assess individual preferences by administering surveys that ask individuals to choose their preferred option between two or more hypothetical scenarios or choice sets. ${ }^{5-7}$ Options are described with a fixed set of attributes and corresponding levels that vary in each scenario. The underlying assumption in a DCE is the respondents' choices are based on maximising their benefit (utility). Through the systematic construction of choice sets and analysis of the respondents' choices, researchers can assess the relative importance of each attribute and acceptable trade-offs among attributes.

In this study, we asked patients to select between two hypothetical nutritional supplements as described by the treatment attributes. Attributes were specifically chosen that reflect different vitamin $\mathrm{D}_{3}$ dosing regimens being used by physicians for patients who had sustained an acute fracture. ${ }^{89}$ Vitamin D was not explicitly referenced in the DCE to avoid bias stemming from patients' prior opinions about vitamin D. 'No supplement' was also provided as a third option in each choice set in the event the patients did not find either hypothetical scenario favourable. The 'no supplement' option assumed a baseline healing time of 16 weeks and a $12 \%$ risk of reoperation for their fracture $^{10-12}$; this was chosen to reflect the clinical course of a surgically treated tibial shaft fracture.

\section{Study setting and population}

We conducted this study at the R Adams Cowley Shock Trauma Center in Baltimore, Maryland. All adult (18-60 years), English-speaking patients treated with an extremity fracture proximal to the hands and feet (carpal
Table 1 Attributes and levels included in the discrete choice experiment

\begin{tabular}{|c|c|c|}
\hline Attributes & Levels & Variable coding \\
\hline $\begin{array}{l}\text { Out-of-pocket } \\
\text { costs }\end{array}$ & $\$ 0, \$ 20, \$ 50, \$ 100$ & Continuous \\
\hline $\begin{array}{l}\text { Healing time } \\
\text { (weeks) }\end{array}$ & $8,12,14,16$ & Continuous \\
\hline Risk of reoperation & $4 \%, 8 \%, 12 \%$ & Continuous \\
\hline $\begin{array}{l}\text { Frequency of } \\
\text { supplementation }\end{array}$ & $\begin{array}{l}\text { Daily, weekly, every } \\
6 \text { weeks, every } \\
12 \text { weeks }\end{array}$ & $\begin{array}{l}\text { Categorical } \\
\text { (effects) }\end{array}$ \\
\hline $\begin{array}{l}\text { Duration of } \\
\text { supplementation }\end{array}$ & $\begin{array}{l}\text { Once, } 6 \text { weeks, } \\
12 \text { weeks, } \\
24 \text { weeks }\end{array}$ & $\begin{array}{l}\text { Categorical } \\
\text { (effects) }\end{array}$ \\
\hline Routine blood test & No, every 6 weeks & $\begin{array}{l}\text { Categorical } \\
\text { (effects) }\end{array}$ \\
\hline
\end{tabular}

or tarsal bones) were assessed for eligibility from July 2016 through October 2016. Patients were enrolled in the study at an outpatient follow-up appointment within 7 weeks from their initial injury. The University of Maryland Institutional Review Board approved the study. All patients provided informed consent prior to their inclusion in the study.

\section{Study design}

Following the International Society for Pharmacoeconomics and Outcomes Research conjoint analyses practice guidelines, ${ }^{13} 14$ the attributes and corresponding levels followed information gathered in literature reviews, patient interviews, expert consultation and a retrospective review of patient outcomes. We further refined the attributes through pilot testing where qualitative patient feedback suggested the removal of a side effect attribute, the inclusion of blood test attribute, the addition of an opt-out option and reframing the healing time and reoperation risk attributes in reference to a baseline. Patients chose between two hypothetical unlabelled supplements (and an opt-out option) that vary in six attributes: duration of healing time; out-of-pocket costs; efficacy in reducing risk of another operation; number of blood tests required during the treatment period; duration of treatment and frequency of administration (table 1). Ultimately, the selection of these six attributes attempted to balance what is important to the respondent and what is relevant to the clinician-prescriber. Attributes for the duration of treatment and frequency of administration were based on a survey of vitamin D supplementation patterns of 397 orthopaedic surgeons. ${ }^{8}$

We developed two surveys, each with 12 distinct choice sets, using a D-optimal design in JMP V.12 software (SAS Institute) to minimise respondent burden and maximise variation in attribute comparison. Each version was a stand-alone fully efficient balanced design. Figure 1 displays the format in which participants received the choices. Patients were randomly administered one of the 
1. Which supplement would you prefer?

\begin{tabular}{|c|c|c|c|}
\hline & Supplement A & Supplement B & No Supplement \\
\hline What will it cost & $\$ 0$ & $\$ 100$ & $\$ 0$ \\
\hline $\begin{array}{l}\text { How long will it take } \\
\text { the fracture to heal }\end{array}$ & 14 weeks & 8 weeks & 16 weeks \\
\hline $\begin{array}{c}\text { How often and long } \\
\text { will you have to take } \\
\text { the pill }\end{array}$ & one time & $\begin{array}{l}\text { once per day } \\
\text { for } 24 \text { weeks }\end{array}$ & $\mathrm{n} / \mathrm{a}$ \\
\hline $\begin{array}{l}\text { Chance you will need } \\
\text { another operation }\end{array}$ & $4 \%$ & $8 \%$ & $12 \%$ \\
\hline $\begin{array}{c}\text { Number of additional } \\
\text { times blood tests are } \\
\text { needed }\end{array}$ & one & none & $\mathrm{n} / \mathrm{a}$ \\
\hline Check one & $\begin{array}{c}\text { Prefer Supplement A } \\
\square\end{array}$ & $\begin{array}{c}\text { Prefer Supplement } \\
\text { B } \\
\square\end{array}$ & $\begin{array}{c}\text { Prefer No } \\
\text { Supplement } \\
\square\end{array}$ \\
\hline
\end{tabular}

Figure 1 Sample question from the discrete choice experiment survey administered to participants. In each question, the values for each hypothetical supplement were varied.

two surveys (available as online supplementary content). A member of the research staff was available for questions as the study participant completed the survey. We collected demographic data including age, sex, race, type of injury, American Society of Anesthesiologists physical status, household income, health insurance status and timing of recruitment from both the survey and the medical record. Patients were asked to identify if they had previously taken supplements prior to their injury, as well as if they were currently taking any other medications on a regular basis and if those treatments required regular blood tests. At the end of the survey, patients had to predict the length of their healing time.

The rule of thumb proposed by Pearmain et alsuggested sample size over 100 respondents provides stable estimates for modelling preference data obtained from DCEs. ${ }^{15}$ Lancsar and Louviere noted reliable models with a minimum of 20 respondents per questionnaire version. ${ }^{5}$ For our study, we sought to recruit 150 participants to ensure reliable estimates of our preference data.

\section{Data analysis}

We performed all statistical analyses using JMP Pro V.13 (SAS Institute). For patient demographic and clinical characteristics, means and SD described continuous variables and frequencies and proportions described categorical variables. We used a hierarchical Bayesian model to estimate the patient preferences (or utility) for each attribute. One advantage of hierarchical Bayesian modelling over more traditional discrete choice analysis is it allows for individual level utility estimates in addition to aggregate estimates. ${ }^{13}$ The Bayesian methodology generates a utility estimate for each individual in the sample and also combines the individual's utility to derive posterior estimates for the sample. Model parameters, including interactions, are calculated iteratively using Gibbs sampling. ${ }^{16}$ In our model, we ran 10000 iterations, including 5000 burn-in iterations. The mean utilities presented in the results for each attribute level represent the mean of these iterations. The utility of each attribute level estimates the strength and direction of the respondents' preference towards a given attribute. Utility values can be positive or negative, with values further from zero indicating a stronger preference. Cost (US dollars), reduction in reoperation risk (absolute per cent) and reduction in healing time (weeks) were modelled as both categorical and continuous variables in the model. Including cost, reduction in reoperation risk and reduction in healing as continuous variables presented the strongest model fit, and were coded as such in the final model. We modelled the frequency of supplementation, the duration of supplementation and the requirement of a blood test using effects coding.

We determined the relative importance of each attribute level by constructing a ratio with the numerator equalling the difference of the maximum value for the levels of a particular attribute and the minimum value for the levels of that same attribute. The denominator of the ratio is the sum of the values obtained in the numerator for all the attributes. This process normalised the scores to sum $100 \%$.

We used marginal rates of substitution to assess acceptable trade-off estimates for varying dosing regimens. Each plausible scenario held a cost of US\$20 and a regular blood draw constant. The frequency and duration of supplementation varied based on plausible regimens, and 
the associated trade-offs for absolute changes in healing time and reoperation rates were assessed.

We performed hierarchical cluster analysis to determine the number of clusters in our sample that best predict preference heterogeneity among respondents. Based on cubic cluster criterion, ${ }^{17}$ we selected three clusters for our sample. Using analysis of variance (ANOVA) and $\chi^{2}$ tests, we compared all patient characteristics by cluster to determine the variables associated with cluster membership. In addition, we compared individual-level utility estimates by cluster using ANOVA and $\chi^{2}$ tests to determine the attributes associated with cluster membership.

\section{Patient involvement}

Patient interviews and our study team's clinical experience with patients informed the selection of attributes and levels for the DCE. The DCE survey was further refined by pilot testing with feedback from patients. No patients were involved in the recruitment to or conduct of the study. The results of this study were not disseminated to the study participants but have informed the design of a patient-centred trial.

\section{RESULTS}

Of the 240 patients screened for participation, 34 (14.2\%) patients declined participation and 7 were excluded as non-English speaking (2.9\%). Of the 199 patients included in the analysis, the mean age was 38.1 years $(\mathrm{SD}$; 13.1 ), with $68.3 \%$ of male sex. The majority of participants had a lower extremity fracture $(58.3 \%)$ and were fully insured $(83.9 \%)$. A significant percentage of participants were unemployed $(27.6 \%)$ and living on a household income below US\$35000 (42.7\%). Nearly a quarter of the participants were currently taking some types of dietary supplement during the study period (table 2).

Respondents selected supplement A or supplement B in 2034 of 2388 completed choice sets (rather than 'prefer no supplement'), suggesting an overall willingness in the sample to use supplementation to improve fracture healing and the included attributes captured important dosing and fracture healing factors. Overall, the attribute with the greatest relative importance to fracture patients' supplementation decisions was the reduction in the risk of reoperation (weighted at $34.3 \%$ ), followed by a reduction in healing time (24.4\%) (figure 2). Requiring a routine blood test $(2.8 \%)$ was the least important attribute contributing to supplementation preferences included in our model. We detected minimal correlation between attribute levels $(r<0.42)$.

The parameter estimates of utilities ( $(B)$ for each attribute level are presented in table 3 . Attributes with a positive utility parameter indicated the attribute would improve patient satisfaction, while attributes with negative utility parameters would lessen the patient's satisfaction. The signs on the parameter estimates were as expected with increased costs and blood tests having a negative effect. Reductions in the risk of reoperation,
Table 2 Characteristics of orthopaedic fracture participants $(n=199)$

\begin{tabular}{lc}
\hline Characteristic & Mean (SD) \\
\hline Male, no. (\%) & $136(68.3)$ \\
\hline Age, year & $38.1(13.1)$ \\
\hline Race, no. (\%) & $111(55.8)$ \\
\hline White & $70(35.2)$ \\
Black & $10(5.1)$ \\
\hline Hispanic & $8(4.0)$ \\
\hline Other & \\
\hline Primary injury, no. (\%) & $116(58.3)$ \\
\hline Lower extremity & $54(27.1)$ \\
\hline Upper extremity & $29(14.6)$ \\
\hline Pelvis/Acetabulum
\end{tabular}

$\mathrm{ASA}^{*}$, no. (\%)

\begin{tabular}{|c|c|}
\hline 1 & $65(32.7)$ \\
\hline 2 & $88(44.2)$ \\
\hline 3 & $40(20.1)$ \\
\hline 4 & $5(2.5)$ \\
\hline 5 & $1(0.5)$ \\
\hline Unknown & $41(20.5)$ \\
\hline \multicolumn{2}{|l|}{ Employment status, no. (\%) } \\
\hline Full time & $107(53.8)$ \\
\hline Unemployed & $55(27.6)$ \\
\hline Part time & $18(9.0)$ \\
\hline Self-employed & $17(8.5)$ \\
\hline Unknown & $41(20.5)$ \\
\hline \multicolumn{2}{|l|}{ Income, no. (\%) } \\
\hline$<$ US\$10000 & $35(17.6)$ \\
\hline US\$10 000-19999 & $6(3.0)$ \\
\hline US\$20 000-34999 & $44(22.1)$ \\
\hline US\$35 000-49999 & $15(7.5)$ \\
\hline US\$50 000-74999 & $30(15.1)$ \\
\hline US\$75 000-100000 & $20(10.1)$ \\
\hline$>$ US\$100000 & $39(19.6)$ \\
\hline Unknown & $10(5.0)$ \\
\hline \multicolumn{2}{|l|}{ Health insurance, no. (\%) } \\
\hline Fully insured & $167(83.9)$ \\
\hline Partially insured & $13(6.5)$ \\
\hline Uninsured & $16(8.0)$ \\
\hline Unknown & $3(1.5)$ \\
\hline Currently using supplements, no. (\%) & $47(23.6)$ \\
\hline Routinely takes medication, no. (\%) & $85(42.7)$ \\
\hline Daily & $76(38.2)$ \\
\hline Weekly & $8(4.0)$ \\
\hline Routine blood test, no. (\%) & $41(20.6)$ \\
\hline Days from injury to survey & $24.8(12.9)$ \\
\hline Anticipated fracture healing time, weeks & $11.6(8.4)$ \\
\hline
\end{tabular}

*ASA physical status classification system for assessing preoperative patient fitness.

ASA, American Society of Anesthesiologists. 


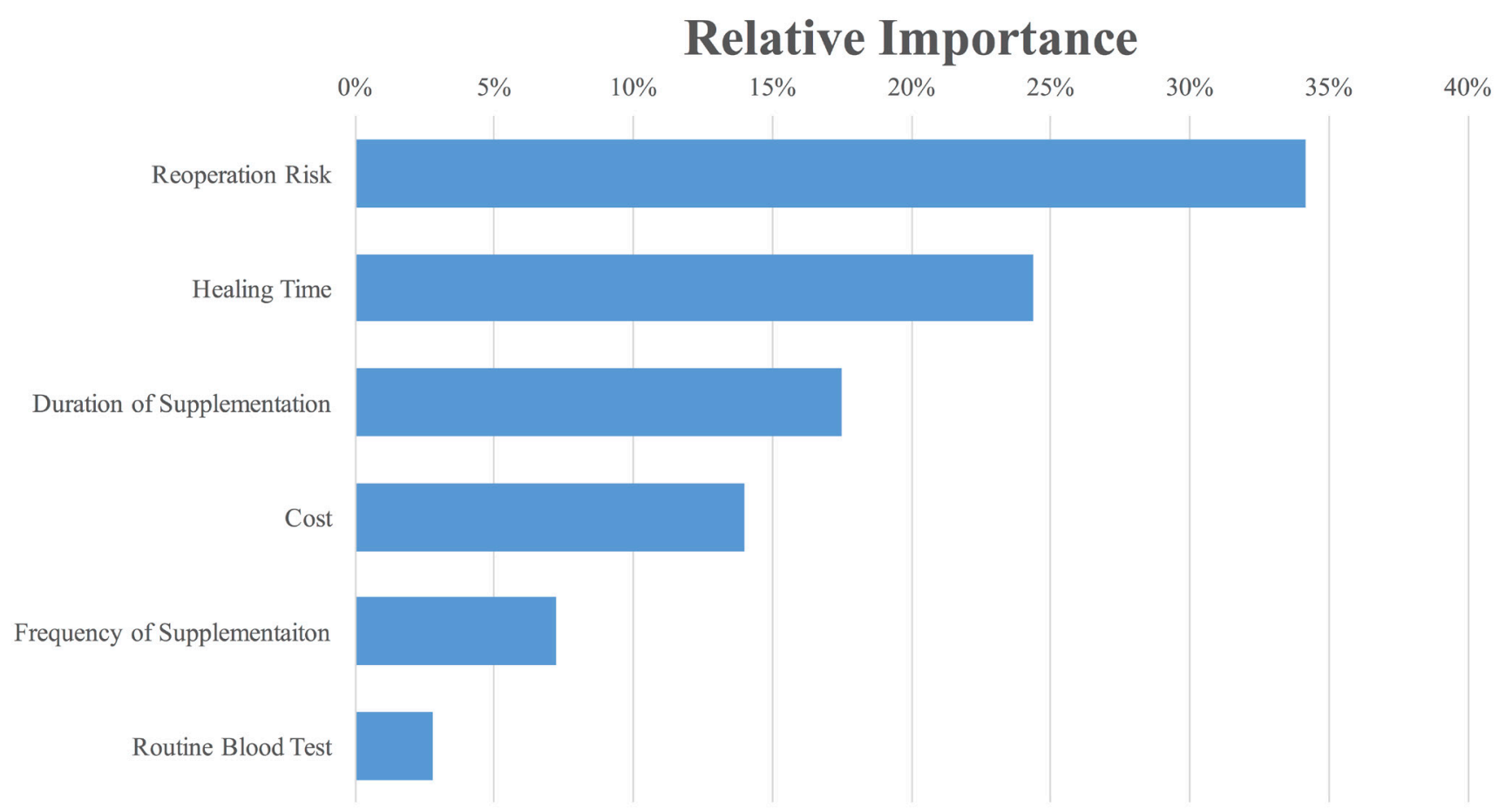

Figure 2 The relative importance across all attributes included in the discrete choice experiment.

reduced healing time, reduced frequency of doses and reduced duration of supplementation had a positive effect. The highest parameter estimates were for a one-time supplementation dose $(\beta=0.71,95 \%$ CI 0.41 to 1.00$)$, followed by a reduction in the risk of reoperation $(B=0.41$ per absolute $\%$ reduction, $95 \%$ CI 0.0 .36 to 0.46$)$ and shortened healing time $(B=0.26$ per week, $95 \%$ CI 0.22 to 0.29$)$. Supplementation for 24 weeks in duration $(\beta=-0.83,95 \% \mathrm{CI}-1.00$ to -0.67$)$ and a daily supplement ( $\beta=-0.29,95 \%$ CI -0.47 to -0.11 ) were associated with the lowest parameter estimates. The 'no supplement' option had a large negative value suggesting patients in the sample population generally desired supplementation.

We modelled several plausible clinical scenarios to understand the reduction in healing time and reoperation risk that patients would require to find potential supplement dosing regimens acceptable (table 4). Responses to the DCE assumed a healing time of 16 weeks and a $12 \%$ risk of reoperation without supplementation. Under these assumptions, we determined acceptable reductions in healing time and risk of reoperation for supplementation taken daily, weekly or every 6 weeks for a period of 12 weeks with a blood test every 6 weeks and a US $\$ 20$ out-of-pocket patient expense. In exchange for daily supplementation for 12 weeks, 2 blood tests and US $\$ 20$ in expense, respondents required either a 4.4-week reduction in healing time, a $2.9 \%$ absolute reduction in reoperation risk or some combination of the two. Similarly, in exchange for a treatment strategy that would require supplements every 6 weeks, 2 blood tests and a cost of US $\$ 20$ during the 3-month postinjury period, patients expected a $2.0 \%$ absolute reduction in the risk of reoperation or a 3.1-week reduction in healing time from the baseline. A smaller reduction in the risk of reoperation, if offset by an increased reduction in healing time or vice-versa would also be acceptable for this potential regimen.

Based on cubic cluster criterion in the hierarchical clustering analysis, three clusters derived from our sample. Eighty per cent of the respondents were members of cluster $1,11 \%$ in cluster 2 and $9 \%$ in cluster 3 (table 5). Cluster membership was significantly associated with household income $(p=0.01)$ and healthcare insurance $(\mathrm{p}=0.049)$. Cluster 2 membership had a disproportionately high proportion of partially insured respondents ( $19 \%$ vs $5 \%$ in cluster $1 \%$ and $6 \%$ in cluster 3 ). Respondents in cluster 3 were more likely to have an annual household income of less than $\$ 10000$ (53\% vs 13\% in cluster $1 \%$ and $31 \%$ in cluster 2 ). There was significant heterogeneity in preferences among the three clusters with respect to the costs of supplement, the reduction in healing time, the reduced risk of reoperation and the 'no supplementation' constant. Cluster 1 members had a very low utility associated with the 'no supplementation' constant $(\beta=-12.85, \mathrm{SE}=0.17)$, suggesting a strong overall willingness in cluster 1 to use supplementation to improve fracture healing. Cluster 2 members were unique in the negative utility associated with the cost of supplementation $(B=-0.06$ per $\mathrm{US} \$ 1, \mathrm{SE}=0.006)$. Cluster 3 members had the highest parameter estimates for a reduction in healing time $(B=0.39$ per week, $\mathrm{SE}=0.03)$ and a reduction 
Table 3 Mean utility calculated using posterior means for each attribute level

\begin{tabular}{|c|c|c|}
\hline Attribute & Level & Mean utility $(95 \% \mathrm{Cl})$ \\
\hline $\begin{array}{l}\text { Cost of supplement } \\
\text { (per US\$1) }\end{array}$ & & $-0.02(-0.02$ to -0.01$)$ \\
\hline $\begin{array}{l}\text { Shortened healing time } \\
\text { (per week) }\end{array}$ & & 0.26 (0.22 to 0.29$)$ \\
\hline $\begin{array}{l}\text { Risk reduction of } \\
\text { reoperation (per \%) }\end{array}$ & & 0.41 (0.36 to 0.46$)$ \\
\hline \multirow{4}{*}{$\begin{array}{l}\text { Frequency of } \\
\text { supplementation }\end{array}$} & Daily & $-0.29(-0.47$ to -0.11$)$ \\
\hline & Weekly & $-0.09(-0.30$ to 0.08$)$ \\
\hline & $\begin{array}{l}\text { Every } \\
6 \text { weeks }\end{array}$ & $0.06(-0.11$ to 0.24$)$ \\
\hline & $\begin{array}{l}\text { Every } \\
12 \text { weeks }\end{array}$ & 0.34 (0.16 to 0.54$)$ \\
\hline \multirow{4}{*}{$\begin{array}{l}\text { Duration of } \\
\text { supplementation }\end{array}$} & Once & 0.71 (0.41 to 1.00$)$ \\
\hline & For 6 weeks & 0.30 (0.12 to 0.49$)$ \\
\hline & For 12 weeks & $-0.23(-0.39$ to -0.07$)$ \\
\hline & For 24 weeks & $-0.83(-1.00$ to -0.67$)$ \\
\hline \multirow[t]{2}{*}{ Routine blood test } & Yes & $-0.12(-0.21$ to -0.04$)$ \\
\hline & No & 0.12 (0.04 to 0.21$)$ \\
\hline $\begin{array}{l}\text { No supplementation } \\
\text { constant }\end{array}$ & & $-11.43(-12.57$ to -10.33$)$ \\
\hline \multicolumn{3}{|l|}{ Model statistics } \\
\hline $\begin{array}{l}\text { Number of } \\
\text { respondents }\end{array}$ & 199 & \\
\hline Total iterations & 10000 & \\
\hline Burn-in iterations & 5000 & \\
\hline $\begin{array}{l}\text { Average log } \\
\text { likelihood after burn- } \\
\text { in }\end{array}$ & -907.49 & \\
\hline
\end{tabular}

Mean utility quantifies the additional satisfaction gained by the patient for each described attribute/level. Negative mean utility values signify an aversion to or dissatisfaction with the described attribute/level.

in the risk of reoperation $(\beta=0.55$ per absolute $\%$ reduction, $\mathrm{SE}=0.06$ ). Cluster 3 exhibited the lowest relative preference to supplementation with a 'no supplementation' constant of $\beta=-3.94(\mathrm{SE}=0.53)$.

\section{DISCUSSION}

Our results indicate patients who have sustained a fracture have a general willingness to use supplementation to improve fracture healing. When evaluating supplement options, the benefits of a reduced risk of reoperation and reduced healing time bear the greatest relative importance. Furthermore, patients gain considerable utility from loading dose, as opposed to daily dose regimens and have a comparable aversion to regimens of 24 weeks in duration. Among possible dosing regimens, patients expect a reduced healing time of 3-4.5 weeks, an absolute reduction in the risk of reoperation of $2 \%-3 \%$ or a combination of the two clinical benefits relative to their baseline. Household income and health insurance status largely predicted heterogeneity in preferences and was associated with variation in mean utilities estimates for costs, healing time, reoperation risk and overall willingness to use supplements.

Based on limited evidence to guide vitamin D treatment decisions, ${ }^{8}{ }^{18}$ orthopaedic surgeons are using numerous different vitamin $\mathrm{D}_{3}$ supplementation treatment regimens to improve healing and decrease the risk of reoperations for healthy, patients with a non-osteoporotic fracture. Similarly, many surgeons believe vitamin D could also decrease the length of time required for healing to occur because of the bone metabolism role of vitamin D during early fracture callus formation. ${ }^{19} \mathrm{By}$ performing this discrete choice experiment, we sought to understand patient values towards the plausible effect of vitamin $\mathrm{D}_{3}$ supplementation on acute fracture healing outcomes.

Previous studies in patients with rheumatoid arthritis have also quantified preferences for different treatment attributes. These investigations found treatment benefits, such as increasing the chance of a major symptom improvement and reducing the chance of serious joint damage were more important than dosing regimen. ${ }^{20}$ These findings are consistent with our study population, in which clinical outcomes were of much greater relative importance when compared with the burden of supplementation. Similarly, our patients also placed more value on limiting the duration of supplementation rather than the frequency of the supplementation. ${ }^{21}{ }^{22}$ In contrast to research on rheumatoid arthritis medications, ${ }^{23}$ cost was of less relative importance to our overall sample. However, our cluster analysis revealed respondents with low annual household incomes and partial insurance to be particularly averse to any incremental increase in the cost of supplementation.

Table 4 Matrix demonstrating potential supplement dosing regimens with acceptable clinical outcomes

\begin{tabular}{|c|c|c|c|c|}
\hline Potential regimen & Levels & \multicolumn{3}{|c|}{ Acceptable trade-offs } \\
\hline $\begin{array}{l}\text { Daily for } 12 \text { weeks with } 2 \text { blood tests } \\
\text { and a cost of US } \$ 20\end{array}$ & Reduced healing time & 4.4 weeks & None & 1.3 weeks \\
\hline \multirow{2}{*}{$\begin{array}{l}\text { Weekly for } 12 \text { weeks with } 2 \text { blood } \\
\text { tests and a cost of US } \$ 20\end{array}$} & Reduced healing time & 3.7 weeks & None & 2.1 weeks \\
\hline & Reduced risk of reoperation & None & $2.4 \%$ & $1.0 \%$ \\
\hline $\begin{array}{l}\text { Every } 6 \text { weeks for } 12 \text { weeks with } 2 \\
\text { blood tests and a cost of US } \$ 20\end{array}$ & Reduced risk of reoperation & None & $2.0 \%$ & $1.0 \%$ \\
\hline
\end{tabular}

Patients were told to assume a baseline fracture healing time of 16 weeks and a $12 \%$ risk of reoperation without supplementation. 
Table 5 Heterogeneity in preferences associated with cluster membership

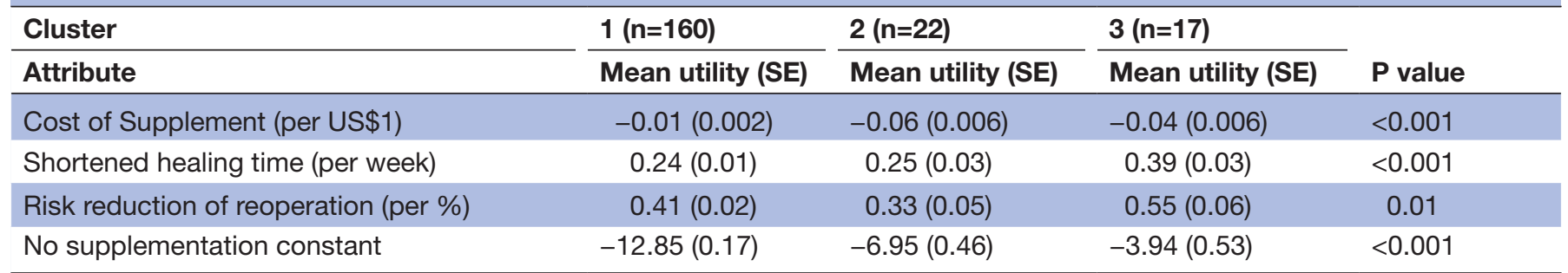

To our knowledge, this is the first study to quantify patient preferences towards using nutritional supplements to improve fracture healing. The marginal rates of substitution enable us to quantify and compare acceptable trade-offs in this patient population. Furthermore, the trade-off assessments provided can guide clinicians to design dosing regimens that will optimise adherence. Our cluster analysis provides insight into which attributes will promote the use of supplements across different segments of the fracture population.

The following limitations must be considered in the context of our study design. We recognise there is an array of other factors that may impact a fracture patient's willingness to use a nutritional supplement. However, we invested considerable time to ensure the attributes and levels included in the model were relevant and important to this patient population. Second, each patient enrolled in the study differed slightly in the stage of his or her recovery process although all patients were within 7 weeks of their injury, and this potential confounder was not significant in our cluster analysis. The survey did not specifically mention vitamin D supplementation, opting to use a more generic term, 'nutritional supplement,' in an attempt to avoid possible preconceptions towards vitamin $\mathrm{D}$ by the respondents. However, we assume the preferences stated in this study to accurately reflect preferences towards vitamin D supplementation. Finally, all study participants had recently suffered an orthopaedic injury and the preferences stated by this population may not be generalisable to other patient populations.

Despite these limitations, we had an adequate sample size and a robust design with clinically relevant attributes. Our findings allowed us to model several plausible clinical scenarios for clinicians to understand how patients value healing time and reoperation within certain supplementation regimens. The frequency and duration options presented to patients in the DCE have all been previously used in clinical practice and could be easily implemented by other physicians. Recognising the increased prescription and attention towards vitamin D supplement for fracture patients, the findings of this study are important for informing clinicians on dosing regimens that reflect patient values and for researchers designing patient-centred clinical trials to test the hypothesised fracture healing benefits of vitamin $\mathrm{D}$.
This study assessed the value patients apply to possible clinical outcomes following a fracture and the acceptability of supplementation, in various doses, as a mechanism to improving those outcomes. When presented with alternative supplementation options, patients placed the greatest emphasis on reducing their risk of reoperation followed by a reduction in healing time. Limiting the duration of supplementation was preferable over reducing the frequency of supplementation. These factors and possible trade-offs among these attributes can guide clinical strategies. The findings are also valuable to the design of future trials evaluating the efficacy of vitamin $\mathrm{D}$ following a fracture, specifically in determining the minimally important clinical difference supplements should provide for patients with fracture.

Acknowledgements The authors thank all of the respondents for their time and participation in the study.

Contributors EN contributed to the literature search, study design, data collection, data interpretation, writing and critical revision. NNO contributed to the literature search, study design, data analysis, data interpretation, writing and critical revision. YD, DWC contributed to the data collection, data interpretation and critical revision. SAS, JDA, MB, MFH and GPS contributed to the literature search, study design, data interpretation and critical revision. All authors have approved the final version of the article submitted and agree to be accountable for all aspects of the work.

Funding This research received no specific grant from any funding agency in the public, commercial or not-for-profit sectors.

Competing interests GPS reports payments for presenting by Zimmer Biomet.

Patient consent Obtained.

Ethics approval University of Maryland School of Medicine, Institutional Review Board.

Provenance and peer review Not commissioned; externally peer reviewed. Data sharing statement № additional data are available.

Open Access This is an Open Access article distributed in accordance with the Creative Commons Attribution Non Commercial (CC BY-NC 4.0) license, which permits others to distribute, remix, adapt, build upon this work non-commercially, and license their derivative works on different terms, provided the original work is properly cited and the use is non-commercial. See: http://creativecommons.org/ licenses/by-nc/4.0/

(c) Article author(s) (or their employer(s) unless otherwise stated in the text of the article) 2018. All rights reserved. No commercial use is permitted unless otherwise expressly granted.

\section{REFERENCES}

1. Ettehad H, Mirbolook A, Mohammadi F, et al. Changes in the serum level of vitamin d during healing of tibial and femoral shaft fractures. Trauma Mon 2014;19:e10946.

2. Whiting PS, Greenberg SE, Thakore RV, et al. What factors influence follow-up in orthopedic trauma surgery? Arch Orthop Trauma Surg 2015;135:321-7. 
3. Hiligsmann M, Dellaert BG, Dirksen CD, et al. Patients' preferences for osteoporosis drug treatment: a discrete-choice experiment. Arthritis Res Ther 2014;16:R36.

4. Krahn M, Naglie G. The next step in guideline development: incorporating patient preferences. JAMA 2008;300:436-8.

5. Lancsar E, Louviere J. Conducting discrete choice experiments to inform healthcare decision making: a user's guide. Pharmacoeconomics 2008;26:661-77.

6. Ryan M, Gerard K. Using discrete choice experiments to value health care programmes: current practice and future research reflections. Appl Health Econ Health Policy 2003;2:55-64.

7. de Bekker-Grob EW, Ryan M, Gerard K. Discrete choice experiments in health economics: a review of the literature. Health Econ 2012;21:145-72.

8. Sprague S, Bhandari M, Devji T, et al. Prescription of vitamin D to fracture patients: a lack of consensus and evidence. J Orthop Trauma 2016;30:e64-9.

9. Haines NM, Kempton L, Seymour R, et al. The effect of acute highdose vitamin $D$ supplementation on fracture union in patients with hypovitaminosis D: A pilot study. Proceeding of the Orthopaedic Trauma Association Annual Meeting. Tampa, FL, 2014.

10. Uhthoff HK, Poitras P, Backman DS. Internal plate fixation of fractures: short history and recent developments. J Orthop Sci 2006;11:118-26.

11. Lanting B, MacDermid J, Drosdowech D, et al. Proximal humeral fractures: a systematic review of treatment modalities. J Shoulder Elbow Surg 2008;17:42-54.

12. Bhandari $\mathrm{M}$, Jeray $\mathrm{KJ}$, Petrisor $\mathrm{BA}$, et al. A trial of wound irrigation in the initial management of open fracture wounds. $N$ Engl $\mathrm{J}$ Med 2015;373:2629-41.

13. Reed Johnson F, Lancsar E, Marshall D, et al. Constructing experimental designs for discrete-choice experiments: report of the ISPOR Conjoint Analysis Experimental Design Good Research Practices Task Force. Value Health 2013;16:3-13.
14. Bridges JF, Hauber AB, Marshall D, et al. Conjoint analysis applications in health-a checklist: a report of the ISPOR good research practices for conjoint analysis task force. Value Health 2011;14:403-13.

15. Pearmain D, Swanson J, Kroes E, et al; Stated preference techniques: a guide to practice. 2nd edn: Steer Davies Gleave and Hague Consulting Group, 1991.

16. Train K. A comparison of hierarchical bates and miximum simulated likelihood for mixed logit. Berkeley: University of California, 2001.

17. Sarle WS, Kuo AH. Cubic clustering criterion. Cary, NC: SAS Institute, 1983.

18. Sprague $S$, Petrisor $B$, Scott $T$, et al. What is the role of vitamin D supplementation in acute fracture patients? A systematic review and meta-analysis of the prevalence of hypovitaminosis D and supplementation efficacy. J Orthop Trauma 2016;30:53-63.

19. Doetsch AM, Faber J, Lynnerup N, et al. The effect of calcium and vitamin D3 supplementation on the healing of the proximal humerus fracture: a randomized placebo-controlled study. Calcif Tissue Int 2004;75:183-8

20. Hazlewood GS, Bombardier C, Tomlinson G, et al. Treatment preferences of patients with early rheumatoid arthritis: a discretechoice experiment. Rheumatology 2016;55:1959-68.

21. Laba TL, Brien JA, Fransen M, et al. Patient preferences for adherence to treatment for osteoarthritis: the MEdication Decisions in Osteoarthritis Study (MEDOS). BMC Musculoskelet Disord 2013;14:160.

22. Poulos C, Hauber AB, González JM, et al. Patients' willingness to trade off between the duration and frequency of rheumatoid arthritis treatments. Arthritis Care Res 2014;66:1008-15.

23. Augustovski F, Beratarrechea A, Irazola V, et al. Patient preferences for biologic agents in rheumatoid arthritis: a discrete-choice experiment. Value Health 2013;16:385-93. 